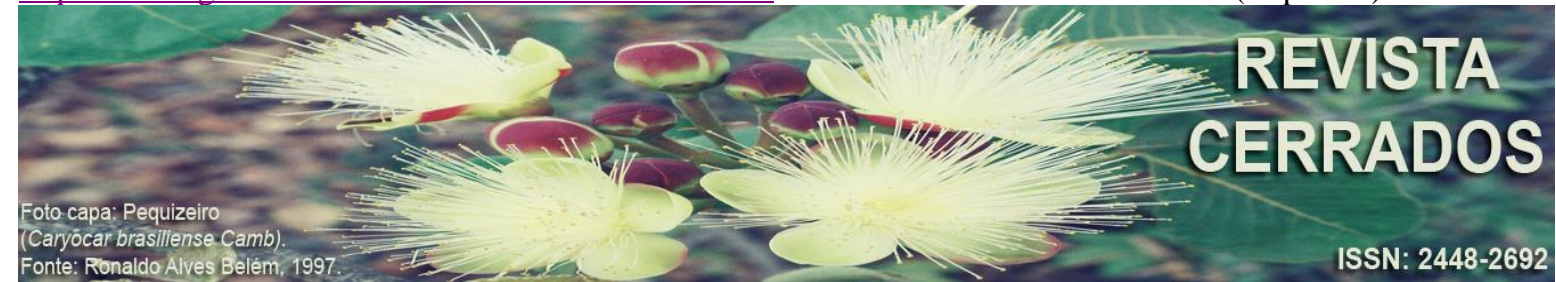

\title{
ANÁLISE DE IMPACTOS AMBIENTAIS EM ÁREA DE PRESERVAÇÃO PERMANENTE (APP) COMO INSTRUMENTO DE GESTÃO EM RIOS URBANOS
}

\author{
ANALYSIS OF ENVIRONMENTAL IMPACTS IN PERMANENT \\ PRESERVATION AREAS (APP) AS A MANAGEMENT INSTRUMENT \\ IN URBAN RIVERS
}

\section{ANÁLISIS DE LOS IMPACTOS AMBIENTALES EN EL ÁREA DE PRESERVACIÓN PERMANENTE (APP) COMO HERRAMIENTA DE GESTIÓN EN RÍOS URBANOS}

\author{
Joice Machado Garcia \\ Pontifícia Universidade Católica de Campinas - PUC-Campinas, Campinas, São \\ Paulo, Brasil \\ E-mail: <joiice_garcia@hotmail.com>. \\ Regina Márcia Longo \\ Pontifícia Universidade Católica de Campinas - PUC-Campinas, Campinas, São \\ Paulo, Brasil \\ E-mail: <regina.longo@uol.com.br>
}

\begin{abstract}
RESUMO
As Áreas de Preservação Permanente (APP) são áreas nas quais a vegetação deve ser mantida, a fim de se garantir a preservação dos recursos hídricos, a estabilidade geológica, a biodiversidade, e consequentemente o bem-estar humano. No entanto, quando localizadas ao entorno dos cursos hídricos, sobretudo em centros urbanos, as APP têm sido transformadas e ocupadas, gerando prejuízos ambientais e sociais. Diante do exposto, o objetivo deste trabalho foi avaliar os impactos ambientais sobre os aspectos água, solo e vegetação na APP do Ribeirão Anhumas em Campinas, São Paulo. Para tanto, utilizou-se de uma abordagem qualiquantitativa com objetivo exploratório, mediante a realização de uma pesquisa de campo e análise documental. Os resultados permitiram inferir que, os usos degradantes do solo aliados a sazonalidade de precipitação influenciam negativamente a qualidade da água do Ribeirão Anhumas. De forma complementar, as amostras de solo colhidas no Alto e Médio Curso indicam baixo teor de matéria orgânica, dificultando a estabilidade e retenção de água e desenvolvimento de vegetação. Verifica-se, portanto, a necessidade de aplicação de medidas
\end{abstract}


GARCIA, J. M.; LONGO, R. M.

Análise de impactos ambientais em Área de Preservação Permanente (APP) como instrumento de gestão em rios urbanos

de correção no solo e no curso d'água, para que estas áreas possam cumprir o estabelecido em legislação e funcionar como elemento de integração urbana e qualidade ambiental.

Palavras-chave: Qualidade ambiental. Bacias urbanas. Recursos hídricos.

\begin{abstract}
Permanent Preservation Areas (APP) are areas in which vegetation must be maintained, in order to guarantee the preservation of water resources, geological stability, biodiversity, and consequently human well-being. However, when located around water courses, especially in urban centers, APPs have been transformed and occupied, generating environmental and social losses. Given the above, the aim of this study was to assess the environmental impacts on water, soil and vegetation in the APP of Ribeirão Anhumas in Campinas, São Paulo. For this purpose, a qualitative and quantitative approach was used with an exploratory objective, by conducting field research and documentary analysis. The results allowed to infer that the degrading uses of the soil allied to the seasonality of precipitation negatively influence the water quality of Ribeirão Anhumas. In a complementary way, the soil samples collected in the High and Medium Course indicate low organic matter content, hindering the stability and water retention and development of vegetation. Therefore, there is a need to apply corrective measures in the soil as well as in the watercourse, so that these areas can comply with the legislation and function as an element of urban integration and environmental quality.
\end{abstract}

Keywords: Environmental quality. Urban basins. Water resources.

\title{
RESUMEN
}

Las Áreas de Preservación Permanente (APP) son áreas en las que se debe mantener la vegetación, para garantizar la preservación de los recursos hídricos, la estabilidad geológica, la biodiversidad y, en consecuencia, el bienestar humano. Sin embargo, cuando se ubican alrededor de cursos de agua, especialmente en centros urbanos, las APP se han transformado y ocupado, generando pérdidas ambientales y sociales. Dado lo anterior, el objetivo de este estudio fue evaluar los impactos ambientales sobre el agua, el suelo y la vegetación en la APP de Ribeirão Anhumas en Campinas, São Paulo. Para este propósito, se utilizó un enfoque cualitativo y cuantitativo con un objetivo exploratorio, mediante la realización de investigaciones de campo y análisis documental. Los resultados permitieron inferir que los usos degradantes del suelo aliados a la estacionalidad de la precipitación influyen negativamente en la calidad del agua de Ribeirão Anhumas. De manera complementaria, las muestras de suelo recolectadas en el curso alto y medio indican un bajo contenido de materia orgánica, lo que dificulta la estabilidad y la retención de agua y el desarrollo de la vegetación. Por lo tanto, es necesario aplicar medidas correctivas en el suelo y en el curso de agua, para que estas áreas puedan cumplir con la legislación y funcionar como un elemento de integración urbana y calidad ambiental.

Palabras-clave: Calidad ambiental. Cuencas urbanas. Recursos hídricos. 
GARCIA, J. M.; LONGO, R. M.

Análise de impactos ambientais em Área de Preservação Permanente (APP) como instrumento de gestão em rios urbanos

\section{INTRODUÇÃO}

A evolução do processo de ocupação das regiões metropolitanas resultou no agravamento de práticas ambientais predatórias, que afetam o conjunto urbano e em especial as áreas ocupadas pela população de baixa renda, com perdas significativas para o funcionamento adequado do conjunto metropolitano. Dentre essas práticas e suas consequências, pode-se citar: o desmatamento, a erosão do solo, as inundações, a poluição do ar e dos mananciais (GROSTEIN, 2001).

É neste contexto que se observa a situação atual da bacia do Ribeirão Anhumas, localizada na região de ocupação urbana mais antiga do município de Campinas, São Paulo (SANTOS, 2002). Toda a região central do município se encontra na área desta bacia, especialmente sobre as nascentes dos córregos que formam o Ribeirão Anhumas (TORRES; ADAMI; COELHO, 2014).

Como produtos resultantes da urbanização e uso agrícola do solo, têm-se a deterioração e/ou destruição de áreas contínuas de vegetação nativa. Grandes áreas de vegetação têm sido transformadas em pequenos fragmentos, e estes, por sua vez, devem ser interligados por meio, por exemplo, de corredores ecológicos, a fim de restabelecer a conectividade entre os fragmentos (METZGER, 2003). Segundo Altoé, Oliveira e Ribeiro (2005), o aproveitamento das Áreas de Preservação Ambiental (APP) como parte do corredor ecológico reduziria possíveis custos quanto à desapropriação de áreas para o reflorestamento nativo, podendo reduzir a área total a ser recomposta se a APP não estiver degradada.

Os impactos verificados nos meios urbano e rural, apesar de atingirem todo o ambiente, no que se trata de recursos hídricos são mais acentuados nos fundos de vale, onde se localiza uma tipologia de APP. Estas são importantes áreas para a manutenção ciliar, equilíbrio hídrico, ecológico e edáfico nas bacias hidrográficas como também de vital importância para a formação de corredores de vegetação que possam vir a unir os fragmentos florestais ao longo de uma bacia hidrográfica antropizada.

Neste contexto, o presente trabalho teve como objetivo avaliar as intervenções humana na APP do Ribeirão Anhumas, localizado no município de Campinas, São Paulo, analisando o uso e ocupação atual nessas áreas e a qualidade da água, do solo e da cobertura vegetal nos três cursos do Ribeirão. 
GARCIA, J. M.; LONGO, R. M.

Análise de impactos ambientais em Área de Preservação Permanente (APP) como instrumento de gestão em rios urbanos

\section{REFERENCIAL TEÓRICO}

\section{Atividades modificadoras do meio e impactos decorrentes}

A transformação do espaço natural como resultado das atividades antrópicas sobre o meio tem se tornado cada vez mais evidente nos últimos tempos. O modelo de desenvolvimento adotado, sobretudo após a revolução industrial tem se mostrado insustentável e prejudicial à paisagem natural, gerando danos socioambientais à saúde das populações silvestre e humana (SOUSA; FERREIRA; MORAES, 2016).

Os problemas ambientais advindos de práticas econômicas predatórias junto ao desperdício dos recursos naturais ocasionam implicações para a sociedade a médio e longo prazos, tornando urgente a elaboração de planejamentos territoriais que busquem integrar elementos socioeconômicos e ambientais (COSTA, 2012).

A ação antrópica é, portanto, um agente modificador relevante do espaço geográfico, sendo a urbanização, a agropecuária, a mineração e a indústria as atividades mais importantes nessa modificação, pois estas alteram o equilíbrio e a dinâmica dos processos naturais, geram novas funções e criam estruturas relacionadas às práticas culturais e o desenvolvimento de uma região (LADWIG; DAGOSTIM; BACK, 2018).

Nesta perspectiva, um dos mais significativos problemas ambientais recentemente têm sido a remoção da cobertura do solo, particularmente o desmatamento e o uso intensivo da terra, resultando em impactos no solo ao passo em que se verifica redução e/ou conversão de áreas florestais em lavouras ou pastagens (SILVA; FELIZMINO; OLIVEIRA, 2015).

\section{Bacias hidrográficas urbanas}

De acordo com Lima e Zákia (2006) a bacia hidrográfica atua como um sistema aberto que recebe energia de agentes climáticos e que perde energia no deflúvio, estando fundamentada em variáveis interdependentes que oscilam em torno de um padrão e, mesmo diante de alterações antrópicas, encontra-se em equilíbrio dinâmico.

A utilização da bacia hidrográfica como unidade de análise permite o planejamento adequado dos recursos hídricos, envolvendo procedimentos que incluem o 
GARCIA, J. M.; LONGO, R. M.

Análise de impactos ambientais em Área de Preservação Permanente (APP) como instrumento de gestão em rios urbanos

levantamento de informações básicas do ambiente, como clima, relevo, geologia, hidrologia, fauna, flora, qualidade da água e aspectos culturais. De posse dessas informações, por meio de uma análise integrada de dados é possível caracterizar e reconhecer, por exemplo, áreas críticas e riscos ambientais (PIASENTIN, 2009).

Com relação às bacias urbanas, estas refletem um quadro ambiental que abrange uma variedade de aspectos naturais e humanos que interagem no tempo e no espaço. Os estudos de geomorfologia urbana têm ajudado a compreender a dinâmica dos processos que estão sendo alterados pela atividade humana e têm resultado na criação de novas formas de relevo, novos solos e modificado os processos fluviais (LUZ et al., 2014).

Quando comparada a uma bacia rural, a bacia urbana possui maior quantidade de superfícies impermeáveis, como telhados, ruas e pisos, produzindo aceleração no escoamento superficial; já as primeiras possuem maior interceptação vegetal, maiores áreas permeáveis; menor escoamento superficial e drenagem mais lenta (SILVA; BARBOSA, 2007).

Em se tratando dos cursos d'água localizados no meio urbano, verifica-se historicamente a ocorrência de degradação e isolamento, e sua presença é comumente relacionada a incômodos tais como mau cheiro, obstáculo à circulação e ameaça de inundações (HULSMEYER; MACEDO, 2015), fazendo com que os cursos hídricos sejam considerados obstáculos ao desenvolvimento das cidades.

Em função da pouca ou má fiscalização, percebe-se que, nestas condições, as APP conceituadas como áreas com a função ambiental de preservar os recursos hídricos são facilmente susceptíveis à descaracterização, dada que são utilizadas de forma incorreta, seja para a disposição de resíduos sólidos ou para ocupação irregular, contribuindo para o agravamento dos problemas de segurança e de limpeza pública (SOUSA, 2008).

Simultaneamente, os níveis de degradação verificados nas APP urbanas exigem forte empenho no incremento e aperfeiçoamento de políticas ambientais urbanas voltadas à recuperação, manutenção, monitoramento e fiscalização destas, a citar-se: a) articulação de estados e municípios para a criação de um sistema integrado de gestão de APP urbanas; b) apoio a novos modelos de gestão de APP urbanas, com participação das comunidades e parcerias com entidades da sociedade civil; e c) definição de normas para a instalação de atividades de esporte, lazer e cultura da população, compatíveis com a função ambiental dessas áreas (SOARES; VAGETTI; SOARES, 2017). 
GARCIA, J. M.; LONGO, R. M.

Análise de impactos ambientais em Área de Preservação Permanente (APP) como instrumento de gestão em rios urbanos

\section{METODOLOGIA}

A bacia hidrográfica do Ribeirão Anhumas tem área aproximada de $150 \mathrm{~km}^{2}$ e está localizada entre as coordenadas $22^{\circ} 45^{\prime} 10^{\prime \prime} \mathrm{S}, 22^{\circ} 55^{\prime} 48^{\prime \prime} \mathrm{S}$ e $47^{\circ} 06^{\prime} 55^{\prime \prime} \mathrm{W}, 46^{\circ} 58^{\prime} 50^{\prime \prime} \mathrm{W}$, disposta majoritariamente sobre o município de Campinas, São Paulo (97\%), enquanto o restante (3\%) localiza-se sobre o município de Paulínia, São Paulo. Com relação às condições climáticas segundo o sistema Koppen, a bacia apresenta clima mesotérmico de inverno seco, com regime típico das zonas tropicais de baixa altitude: verão chuvoso e inverno seco. Os dados de temperatura assinalam valores inferiores a $18^{\circ} \mathrm{C}$ durante o inverno e superiores a $24^{\circ} \mathrm{C}$ durante o verão (TORRES; ADAMI; COELHO, 2014).

Ainda, a bacia de estudo abrange uma área de vegetação transicional, caracterizada por uma parcela de Floresta Ombrófila Densa, associada à latossolos vermelhos, com abundância de lianas e ocorrência de temperaturas elevadas, e outra parte representada por Áreas de Tensão Ecológica, que pode ocorrer na forma de ecótono, na qual a transição é caracterizada pela mistura florística, ou na forma de encrave quando existe uma transição edáfica (AGEITEC, 2019).

Os levantamentos de campo foram realizados em dezembro de 2017 e junho de 2018, a fim de se levantar a influência da sazonalidade climática sobre os parâmetros de qualidade de água, solo e vegetação. Estabeleceram-se três pontos estratégicos ao longo da APP do Ribeirão Anhumas: um em cada curso (Baixo - BC, Médio - MC e Alto - AC), cujas coordenadas são, respectivamente, $\mathrm{AC} 22^{\circ} 52^{\prime} 34.69^{\prime}$ ' S e 4702'6.25" W (próximo à Praça

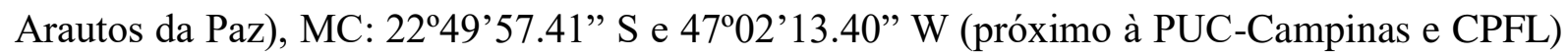

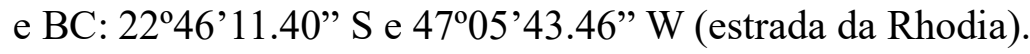

O mapeamento e caracterização do uso e ocupação do solo na bacia do Ribeirão Anhumas se deu por meio de técnicas de sensoriamento remoto. As imagens orbitais datam do ano de 2010 e foram obtidas pela plataforma da Empresa Paulista de Planejamento Metropolitano (EMPLASA, 2010). Tais imagens foram comparadas com imagens do Google Earth PRO - Image $(2016$ DigitalGlobe que datam de 2016 havendo checagem em campo das informações durante as datas de amostragem.

Utilizando o software ArcGIS® Desktop, a imagem orbital foi georreferenciada e projetada segundo o Datum SIRGAS 2000 UTM Zone 23S. As imagens foram sobrepostas e 
GARCIA, J. M.; LONGO, R. M.

Análise de impactos ambientais em Área de Preservação Permanente (APP) como instrumento de gestão em rios urbanos

o sistema de uso e ocupação do solo reclassificado em seis grupos que englobam as classes originais: recursos hídricos (cursos d'água, lagos e represas); solo exposto (mesma classe original); áreas edificadas (loteamentos, grandes equipamentos, áreas edificadas); áreas rurais (pastagem, cultura temporária, semiperene e perene); áreas verdes preservadas (mata e reflorestamento) e áreas verdes degradadas (área úmida, canteiro central de vias públicas, parques, praças, campo natural).

Para a análise das amostras de água utilizaram-se os parâmetros apresentados na Tabela 1, sendo os dados comparados com os limítrofes estabelecidos na Resolução CONAMA 357 de 2005 (BRASIL, 2005). Os parâmetros de solo analisados encontram-se descritos também na Tabela 1, sendo a interpretação destes dada segundo limites do "Manual de Intepretação da Análise do Solo" da Empresa de Pesquisa Agropecuária de Minas Gerais (PEDROSO NETO; COSTA, 2012), do Boletim Técnico 100 do Instituto Agronômico de Campinas (RAIJ et al., 1987) e do manual "Interpretação dos resultados da análise química do solo para culturas anuais" da Empresa Brasileira de Pesquisa Agropecuária (SOUSA; LOBATO, 2004).

Tabela 1: Parâmetros de qualidade da água e do solo e seus respectivos métodos de medição

\begin{tabular}{|c|c|c|c|}
\hline Aspecto & Parâmetros & Método de medição & Fonte \\
\hline \multirow{9}{*}{ ÁGUA } & Oxigênio dissolvido & Oxímetro & CETESB (2011) \\
\hline & $\mathrm{pH}$ & Potenciômetro & BRASIL (2013) \\
\hline & Temperatura & Oxímetro & BRASIL (2013) \\
\hline & Turbidez & Turbidímetro & BRASIL (2013) \\
\hline & $\operatorname{DBO}(5,20)$ & Oxímetro e incubação & APHA (2005) \\
\hline & Condutividade elétrica & Condutivímetro & CETESB (2011) \\
\hline & Sólidos totais & Gravimetria & APHA (2005) \\
\hline & Fósforo total & Método do ácido ascórbico & APHA (2005) \\
\hline & $\begin{array}{l}\text { Coliformes } \\
\text { termotolerantes }\end{array}$ & Tubos múltiplos & BRASIL (2013) \\
\hline \multirow{5}{*}{ SOLO } & $\mathrm{pH}$ & $\mathrm{CaCl} 2$ & \multirow{5}{*}{ Teixeira et al. (2017) } \\
\hline & $\begin{array}{l}\text { Teor de Matéria } \\
\text { Orgânica }\end{array}$ & $\begin{array}{l}\text { Oxidação pelo H2SO4 e } \\
\text { quantificação colorimétrica }\end{array}$ & \\
\hline & Fósforo disponível & Quantificação colorimétrica & \\
\hline & $\begin{array}{l}\text { Teor de potássio, } \\
\text { cálcio e magnésio }\end{array}$ & $\begin{array}{l}\text { Espectrofotometria de absorção } \\
\text { atômica }\end{array}$ & \\
\hline & $\begin{array}{c}\text { Capacidade de Troca } \\
\text { Catiônica (CTC) }\end{array}$ & $\begin{array}{l}\text { Soma dos cátions básicos } \\
(\mathrm{Ca} 2+, \mathrm{Mg} 2+\mathrm{e} \mathrm{K}+) \text { e dos } \\
\text { ácidos }(\mathrm{H}+\mathrm{e} \mathrm{Al} 3+)\end{array}$ & \\
\hline
\end{tabular}

Fonte: Autoria, 2018. 
GARCIA, J. M.; LONGO, R. M.

Análise de impactos ambientais em Área de Preservação Permanente (APP) como instrumento de gestão em rios urbanos

O parâmetro tomado para análise da vegetação nas APP foi o Índice de Área Foliar (IAF), calculado pela análise de fotografias hemisféricas, capazes de mapear o tamanho, a magnitude e distribuição das aberturas da copa em relação ao local em que a fotografia foi obtida (GALVANI; LIMA, 2014). As fotografias foram analisadas no software HemiView@. Para interpretação dos resultados, utilizou-se escala proposta por Oliveira et al. (2011).

Para fins de análises estatísticas dos dados, realizou-se a Análise de Componentes Principais (ACP) no software SAS University, a fim de compreender as interações entre os parâmetros analisados, bem como entender aqueles mais relevantes para a análise de qualidade ambiental de cada ponto estudado.

\section{RESULTADOS E DISCUSSÃO}

De modo geral, conforme já levantado por trabalhos anteriores, tais como Carpi Júnior et al. (2006) e Torres, Adami e Coelho (2014), a bacia se encontra altamente antropizada, sendo o Alto Curso a região com maiores índices de urbanização. Em contrapartida, a região do Baixo Curso se caracteriza por apresentar grande extensão de área rural e tendência de ocupação mais recente. Já no Médio Curso, encontra-se leve sobreposição de áreas edificadas sobre áreas rurais, sendo que, ainda neste curso, as planícies fluviais possuem as piores condições ambientais da bacia, com ocupações de baixa renda próximas ao leito do Ribeirão Anhumas.

Com relação às APP, a Figura 1 possibilita visualização dos diferentes usos e ocupação na APP do Ribeirão Anhumas levando em consideração a área mínima de APP de 30 metros. A ocupação na APP do Ribeirão Anhumas em seu Baixo Curso se dá majoritariamente por áreas rurais, representando $21 \%$ da área rural deste curso e, portanto, em consonância com o uso predominante no curso em geral. Já no Médio e Alto Curso, o uso preponderante na APP se dá por áreas edificadas, confirmando o alto grau de interferência antrópica na mesma em benefício da urbanização. 
GARCIA, J. M.; LONGO, R. M.

Análise de impactos ambientais em Área de Preservação Permanente (APP) como instrumento de gestão em rios urbanos

Figura 1: Uso e ocupação do solo na Área de Preservação Permanente do Ribeirão Anhumas

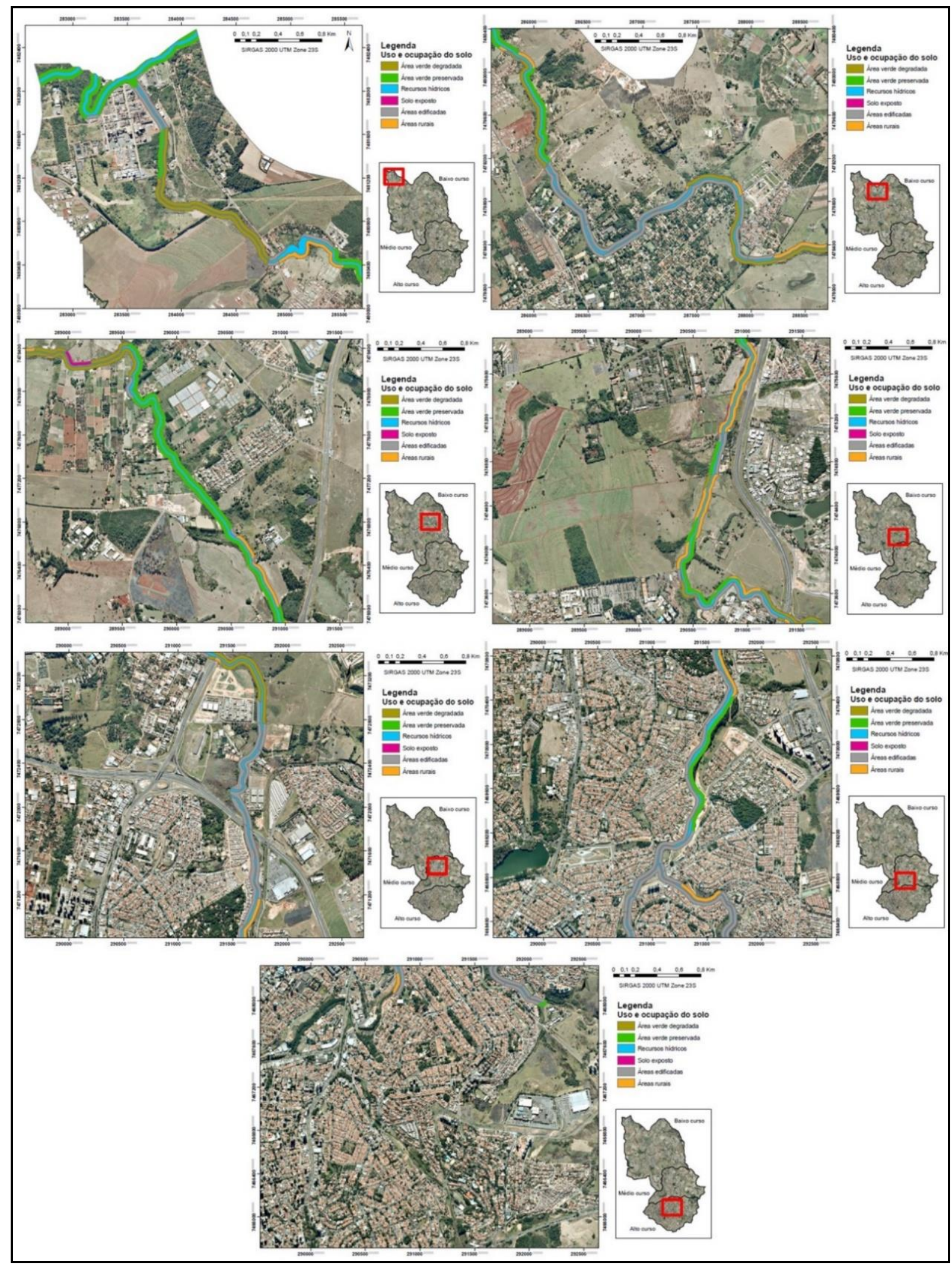

Fonte: Autoria, 2018. 
GARCIA, J. M.; LONGO, R. M.

Análise de impactos ambientais em Área de Preservação Permanente (APP) como instrumento de gestão em rios urbanos

Em se tratando de recursos hídricos, a influência das atividades humanas sobre a bacia é refletida nos parâmetros físico-químicos e biológicos da água (MENEZES et al., 2016). Desta forma, os resultados apresentados na Figura 2 se referem às amostras coletadas nos meses de dezembro/2017 (período chuvoso) e junho/2018 (período seco).

Figura 2: Análise dos parâmetros de qualidade hídrica nos pontos amostrados no Ribeirão Anhumas, Campinas, São Paulo

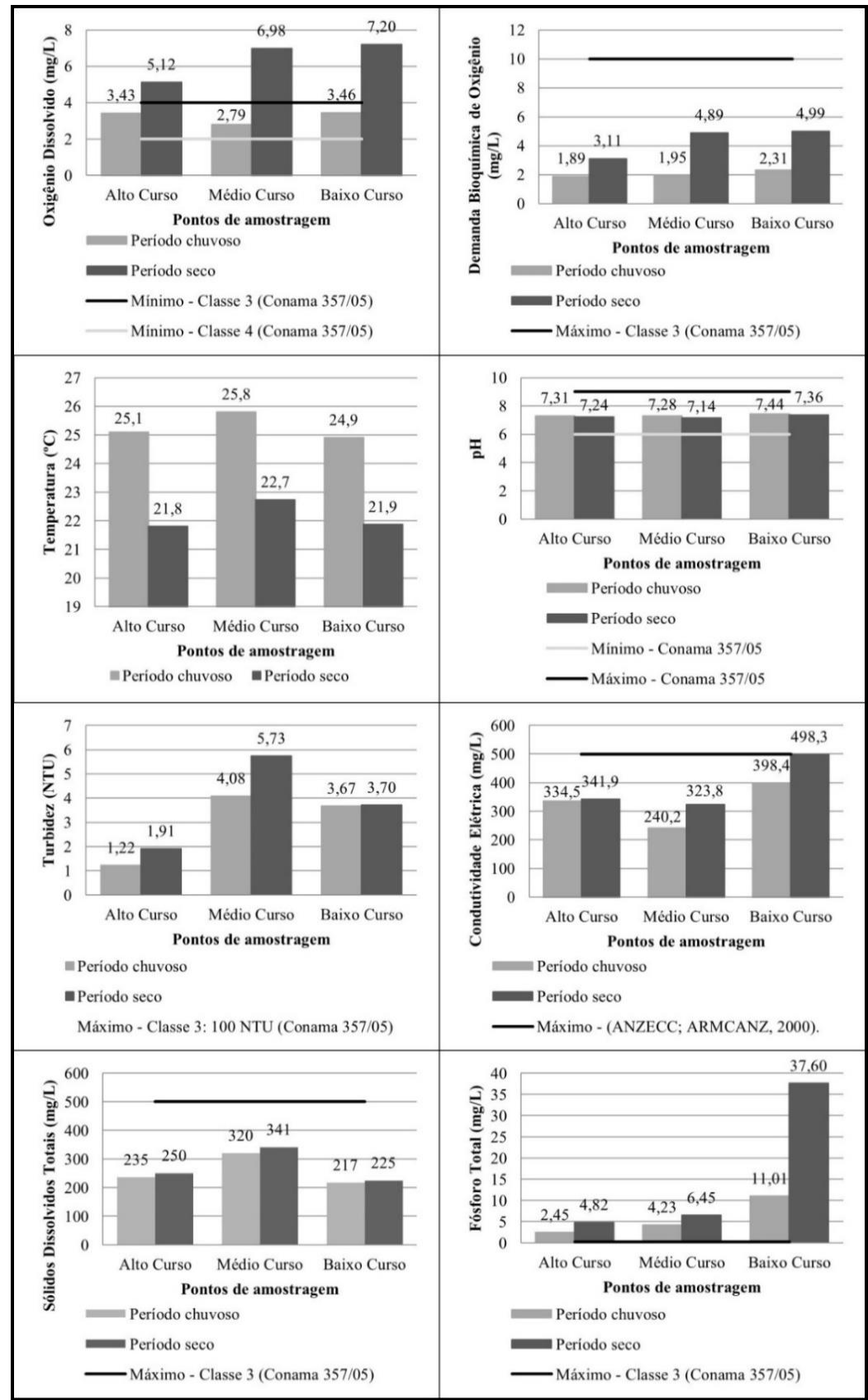

Fonte: Autoria, 2018.

Revista Cerrados, Montes Claros/MG, v.18, n. 1, p. 107-128, jan./jun.-2020 
GARCIA, J. M.; LONGO, R. M.

Análise de impactos ambientais em Área de Preservação Permanente (APP) como instrumento de gestão em rios urbanos

O efeito de diluição é um fator importante na época de chuva, pois com maior volume de água, os teores de elementos decrescem, reduzindo a probabilidade de contaminação (LOBÓN et al., 2015). Tal fato pode ser comprovado com o presente estudo: na coleta de dezembro, que apresenta precipitação acumulada superior a junho, verifica-se teor de OD reduzido, bem como turbidez, condutividade elétrica, sólidos dissolvidos totais e fósforo total. Tal constatação de decréscimo nos parâmetros em período de chuva também foi verificada por Silva et al. (2008), Basso, Moreira e Pizzato (2011) e Souza e Souza (2015).

Outros parâmetros de resultado significativo são fósforo total e coliformes: ambos apresentaram valores que extrapolaram os limites da legislação nas duas amostragens, reflexo da ausência da mata ciliar nas margens do Ribeirão Anhumas. Tal resultado está em consonância com o analisado por Torres, Adami e Coelho (2014), que concluíram que a bacia em estudo apresenta riscos relacionados à degradação da cobertura vegetal e situações de risco ambiental relativos a precipitação e escoamento superficial nas APP.

Correlacionando os parâmetros de qualidade de água analisados com o uso e ocupação do solo na bacia é visível que, apesar da ocupação urbana no Alto Curso, os valores obtidos para os parâmetros analisados são inferiores àqueles do Médio e Baixo Curso, haja vista a ausência de influência anterior. Entretanto, a ocorrência de alguns parâmetros acima do estabelecido em legislação, tais como coliformes termotolerantes e fósforo, evidenciam o despejo de cargas orgânicas no Ribeirão.

Já no Médio Curso, o uso simultâneo de ocupação urbana e rural incide em dados elevados para os parâmetros de turbidez e SDT, devido ao escoamento superficial que promove o arraste de matéria orgânica, partículas de solo e resíduos sólidos para o corpo hídrico. Resultado semelhante também foi encontrado na literatura, tal como por Horbe et al. (2005) ao estudarem o rio Puraquequara localizado na zona rural leste do município de Manaus e por Silva et al. (2008) no estudo do Rio Purus na porção sudoeste da Amazônia.

No Baixo Curso, por sua vez, o processo recente de urbanização favorece o despejo de efluentes muitas vezes sem tratamento ou com tratamento que não atende a legislação, denotando um aspecto de degradação. Neste, pode ser identificada a presença de espumas e resíduos, conferindo às águas um aspecto degradante em termos de qualidade, contribuindo para a perda da função ecológica, servindo apenas como um curso de água de 
GARCIA, J. M.; LONGO, R. M.

Análise de impactos ambientais em Área de Preservação Permanente (APP) como instrumento de gestão em rios urbanos

afastamento de efluentes. A Figura 3 apresenta os valores encontrados para os parâmetros de solo avaliados nos dois períodos amostrados.

Figura 3: Análise dos parâmetros de qualidade do solo nos pontos amostrados no Ribeirão Anhumas, Campinas, São Paulo

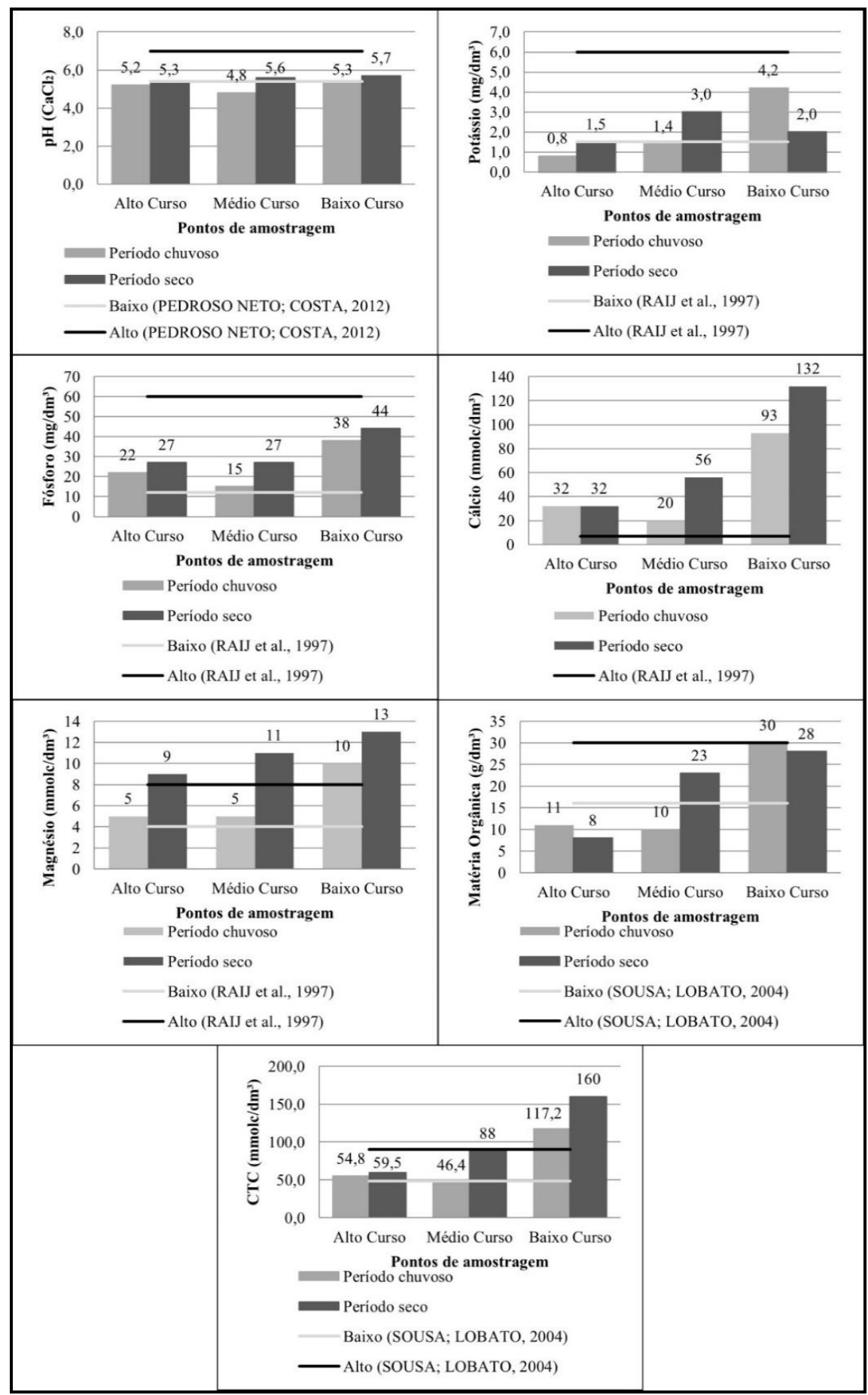

Fonte: Autoria, 2018.

Revista Cerrados, Montes Claros/MG, v.18, n. 1, p. 107-128, jan./jun.-2020 
GARCIA, J. M.; LONGO, R. M.

Análise de impactos ambientais em Área de Preservação Permanente (APP) como instrumento de gestão em rios urbanos

Os valores encontrados indicam que a acidez do solo dos cursos amostrados é baixa quando levado em consideração o fator agronômico. A acidez é comum em regiões onde a precipitação é suficientemente elevada para lixiviar quantidades apreciáveis de bases permutáveis (como o cálcio e o magnésio) na água de drenagem. Em condições elevadas de acidez dos solos, podem ocorrer também teores solúveis de outros metais, como manganês e ferro, tóxicos para as plantas quando em quantidades excessivas (YOSHIOKA; LIMA, 2005).

Quando analisado o teor de fósforo, verificou-se concentração média para os pontos amostrados no Alto e Médio Curso e alta concentração no Baixo Curso. A legislação brasileira não reconhece o fósforo como contaminante de solo, e no caso de áreas agrícolas, a percepção do agricultor para a adubação fosfatada obedece a critérios produtivos e econômicos, não ambientais. No entanto, a utilização de fertilizantes acarreta transporte destes para os cursos d'água, podendo ocasionar a eutrofização (KLEIN; AGNE, 2013).

A concentração dos nutrientes no solo variou de ponto para ponto, sendo majoritariamente excessiva para os três parâmetros analisados: potássio, cálcio e magnésio, com exceção do ponto do Alto Curso que apresentou deficiência de potássio. O potássio é um macronutriente essencial para as plantas, entretanto, por meio do processo de lixiviação, este nutriente pode se apresentar indisponível para as plantas, sendo este processo mais expressivo em solos com baixa CTC (GARCIA et al., 2015).

Na análise do teor da matéria orgânica, pode-se notar a presença de valores baixos no Alto e Médio Curso, sendo inferiores à média do Estado de São Paulo, que se encontra em torno de 29,9 g/dm³ (KIEHL, 1979). A escassez de matéria orgânica, importante propriedade química, permite inferir que nos locais amostrados predomina material mineral, atribuído à retirada e/ou a inexistência de cobertura vegetal densa.

Segundo Tognon, Demattê e Demattê (1998), o teor de matéria orgânica nos solos é influenciado por uma série de fatores e o clima atua como um forte componente: constatouse que o teor de matéria orgânica aumenta logaritmicamente de acordo com o aumento da umidade e decresce exponencialmente com o aumento da temperatura.

O maior valor de CTC foi encontrado no Baixo Curso, o que pode ser atribuído à acidez baixa, confirmando a correlação positiva entre o $\mathrm{pH}$ e o aumento da CTC.

As fotografias hemisféricas dos pontos em estudo e seus respectivos IAFs estão dispostas na Tabela 2. 
GARCIA, J. M.; LONGO, R. M.

Análise de impactos ambientais em Área de Preservação Permanente (APP) como instrumento de gestão em rios urbanos

Tabela 2: Fotografias hemisféricas dos pontos amostrados nos meses de estudo

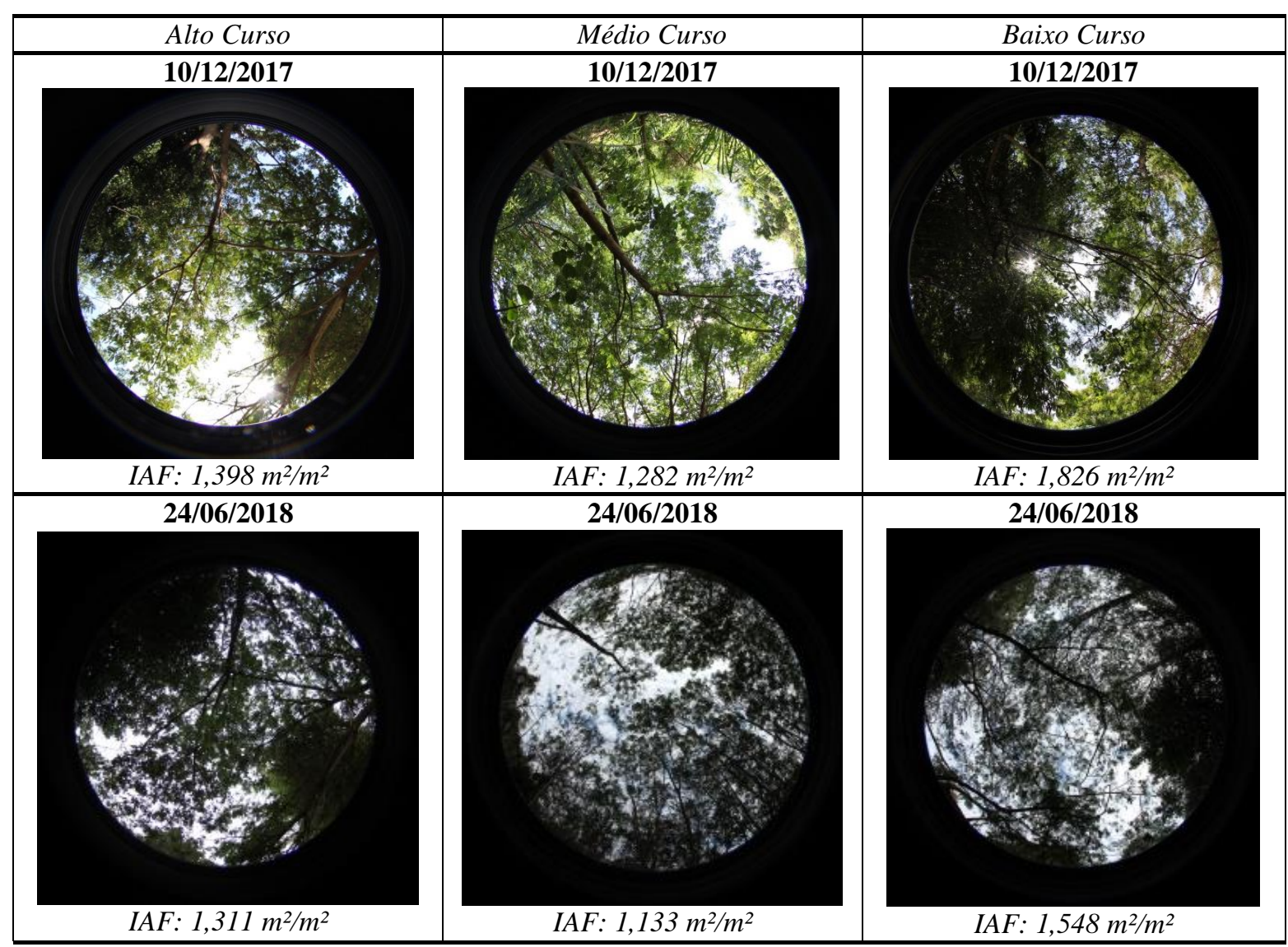

Fonte: Autoria, 2018.

Os valores encontrados neste estudo se adequaram ao estudo de Oliveira (2013) de tal forma que aqueles do Alto e Médio Curso se caracterizaram como pontos de vegetação com porte arbóreo arbustivo e os do Baixo, por sua vez, indicaram a presença de vegetação mais densa. A análise dos valores obtidos permitiu visualizar decaimento, ainda que pouco significativo para o IAF nos três pontos amostrados quando analisados os meses de amostragem. A supressão e a retirada da cobertura vegetal estão diretamente associadas ao aumento das construções nas áreas urbanas, principalmente no que tange as margens dos cursos hídricos.

Em estudo realizado no fragmento florestal Mata de Santa Genebra em Campinas/SP, Garcia et al. (2018) verificaram que o parâmetro IAF é sensível ao efeito de borda, de forma que o mesmo, obtido para trechos internos da mata são na maioria dos casos superiores àqueles localizados na borda do fragmento. De forma similar, Oliveira et al (2011), observaram por meio de estudos realizados na Mata da Várzea - Recife, PE que os 
GARCIA, J. M.; LONGO, R. M.

Análise de impactos ambientais em Área de Preservação Permanente (APP) como instrumento de gestão em rios urbanos

valores de IAF mais próximos à área urbana indicam a redução da cobertura vegetal se comparado aos valores identificados no centro do fragmento e em áreas com baixa interferência antrópica.

Ao comparar os valores de IAF para os pontos amostrados, verificou-se que o Baixo Curso apresentou as melhores condições de vegetação na APP do Ribeirão Anhumas. Em contrapartida, no Alto Curso, onde o ponto de coleta se localiza em meio a área urbana é compreensível que o IAF tenha sido reduzido quando comparado aos outros dois em virtude do sufocamento decorrente do processo de urbanização. Resultados similares também foram observados nos remanescentes florestais localizados na mesma bacia hidrográfica (LONGO et al., 2018; LONGO et al., 2019) apontando que no Baixo Curso, onde se encontram as áreas menos urbanizadas, também são verificadas as melhores qualidades ambientais dos remanescentes florestais. Considerando os parâmetros analisados para água, solo e vegetação, aplicou-se o método de Análise de Componentes Principais para os dois períodos de amostragem do estudo, e os resultados encontram-se na Figura 4.

Figura 4: Análise de componentes principais: a) Amostragem dezembro/2017; b) Amostragem junho/2018
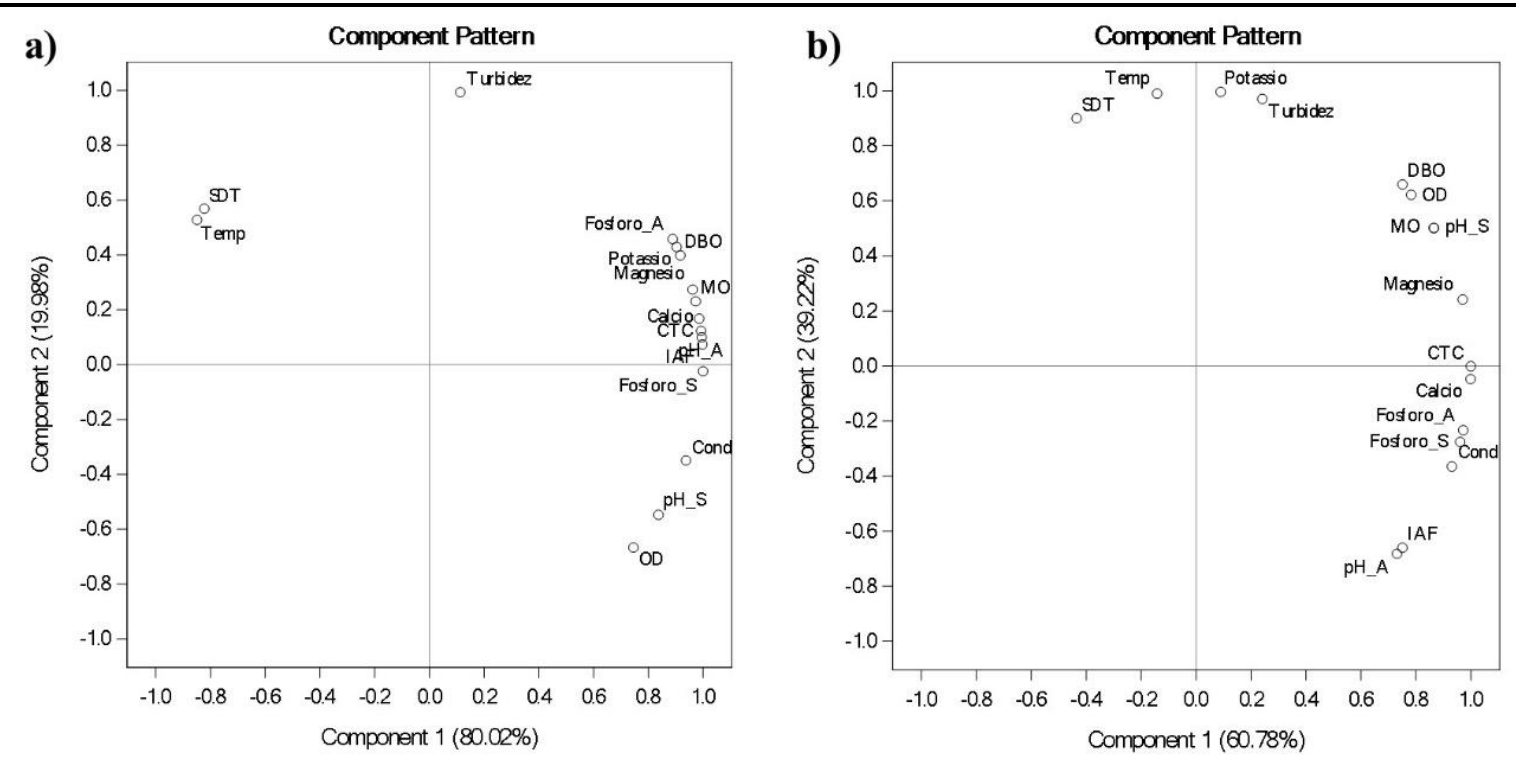

Onde: OD (Oxigênio Dissolvido), DBO (Demanda Bioquímica de Oxigênio), Temp (Temperatura), Cond (Condutividade Elétrica), SDT (Sólidos Dissolvidos Totais), CTC (Capacidade de Troca Catiônica), MO (Teor de Matéria Orgânica), IAF (Índice de Área Foliar), e parâmetros com sufixo_A (Fósforo_A, pH_A), referem-se as amostras de água, e parâmetros com sufixo_S(Fósforo_S, pH_S, referem-se as amostras de solo). Fonte: Autoria, 2018. 
GARCIA, J. M.; LONGO, R. M.

Análise de impactos ambientais em Área de Preservação Permanente (APP) como instrumento de gestão em rios urbanos

Em ambos os casos, a análise por componentes principais evidenciou que $100 \%$ da variância total foi explicada pelas duas primeiras componentes. Na amostragem referente ao mês de dezembro/2017 (Figura 4a), verificou-se que praticamente todas as variáveis, incluindo parâmetros de água, solo e vegetação, encontraram-se fortemente explicadas pela Componente 1, seja positivamente, como os parâmetros Fósforo_A, DBO, Potássio, Magnésio, MO, Cálcio, CTC, pH_A, IAF, Fósforo_S, Cond, pH_S e OD (apresentaram fatores entre 0,8 e 1,0), quanto negativamente para o caso das variáveis SDT e Temp (fator próximo a -0,8). Identificou-se também correlação entre os parâmetros Fósforo_S, Cond, pH_S e OD. Com relação à turbidez, não foi identificada forte correlação com as outras variáveis, estando esta unicamente associada à Componente 2 (fator muito próximo a 1,0).

Quando analisado o segundo período de amostragem (junho/2018 - Figura 4b), a distribuição das variáveis no eixo se fez de forma mais dispersa, indicando menor associação entre as mesmas. No entanto, é possível notar certo grau de semelhança com o primeiro gráfico no comportamento das variáveis DBO, MO, Magnésio, CTC, Fósforo_S e Cond. Novamente os parâmetros de SDT e Temp encontram-se isolados das demais, mas correlacionados entre si e explicados, por sua vez, pela Componente 2, que também está fortemente associada à variável potássio e turbidez (fatores próximos a 1,0). A ausência de correlação do parâmetro de temperatura com os outros levantados, a citar-se $\mathrm{pH}$, fósforo total e condutividade elétrica também foi verificado por Souza et al. (2017) na análise da água de abastecimento público em Goiás.

\section{CONCLUSÕES}

A bacia hidrográfica do Ribeirão Anhumas apresenta alto grau de urbanização em sua APP, especialmente no Alto e Médio Curso. A urbanização e utilização de terras para uso agrícola implica em modificações na paisagem natural, e com a consequente retirada de vegetação, parâmetros de qualidade do solo $(\mathrm{pH}$, teor de potássio, fósforo, cálcio e matéria orgânica) e da água (OD, fósforo total e coliformes termotolerantes) são alterados negativamente.

Os impactos incidentes sobre a qualidade de água concentram-se na extrapolação dos limites estabelecidos pela legislação CONAMA 357/05 para os parâmetros de fósforo 
GARCIA, J. M.; LONGO, R. M.

Análise de impactos ambientais em Área de Preservação Permanente (APP) como instrumento de gestão em rios urbanos

total e coliformes termotolerantes, evidenciando o acúmulo de despejos orgânicos no curso em análise. Já as amostras de solo colhidas no Alto e Médio Curso indicam baixo teor de matéria orgânica, dificultando a estabilidade do solo e retenção de água e consequente desenvolvimento de vegetação. O Índice de Área Foliar obtido para os pontos analisados sugere decaimento na densidade vegetativa quando comparados os meses de análise, sendo inferior na coleta de junho/18.

\section{AGRADECIMENTOS}

O presente trabalho foi realizado com apoio da Coordenação de Aperfeiçoamento de Pessoal de Nível Superior - Brasil (CAPES) - Código de Financiamento 001.

\section{REFERÊNCIAS}

AGEITEC. Agência Embrapa de Informação Tecnológica. Árvore do Conhecimento. Glossário. Disponível em: http://www.agencia.cnptia.embrapa.br/gestor/especies_arboreas_brasileiras/arvore/CONT000 g08hphpk02wx5ok026zxpg7c9wrkm.html. Acesso em: 20 ago. 2018

ALTOÉ, R. T.; OLIVEIRA, J. C.; RIBEIRO, C. A. Á. S. Sistema de informações geográficas na definição de corredores ecológicos para o município de Conceição da Barra - ES. Anais do Simpósio Brasileiro de Sensoriamento Remoto, Goiânia, GO, Brasil, 12. 2005. Disponível em: <http://marte.sid.inpe.br/col/ltid.inpe.br/sbsr/2004/11.20.16.25.12/doc/1995.pdf >. Acesso em: 10 mai. 2019

APHA. American Public Health Association. (2005). Standard Methods for the Examination of Water and Wastewater. Washington: APHA.

BASSO, L. A.; MOREIRA, L. G. R.; PIZZATO, F. A influência da precipitação na concentração e carga de sólidos em cursos d'água urbanos: o caso do arroio Dilúvio, Porto Alegre-RS. Geosul, v. 26, n. 52, p. 145-16, 2011. https://doi.org/10.5007/2177$\underline{5230.2011 \mathrm{v} 26 \mathrm{n} 52 \mathrm{p} 145}$

BRASIL. Resolução n³57, de 17 de março de 2005. Dispõe sobre a classificação dos corpos de água e diretrizes ambientais para o seu enquadramento, bem como estabelece as condições e padrões de lançamento de efluentes. Diário Oficial da União de 18 de março de 2005. p.58-63. Disponível em: 〈http://www2.mma.gov.br/port/conama/legiabre.cfm?codlegi=459>. Acesso em: 23 ago. 2019.

BRASIL. Fundação Nacional de Saúde. Manual prático de análise de água. 2013. Brasília: Fundação Nacional de Saúde (FUNASA). Disponível em: <http://www.funasa.gov.br/site/wpcontent/files_mf/manual_pratico_de_analise_de_agua_2.pdf $>$. Acesso em: 23 set. 2018. 
GARCIA, J. M.; LONGO, R. M.

Análise de impactos ambientais em Área de Preservação Permanente (APP) como instrumento de gestão em rios urbanos

CARPI JUNIOR, S. et al. Levantamento de riscos ambientais na bacia do ribeirão das

Anhumas. In: TORRES, R. B. et al. Recuperação ambiental, participação e poder público: uma experiência em Campinas. p. 262-302, 2006. Campinas: IAC/UNICAMP. Disponível em:

$<$ http://www.iac.sp.gov.br/projetoanhumas/pdf/riscos_ambientais_bacia_ribeirao_anhumas.pd f>. Acesso em: 02 ago. 2018.

CETESB. Companhia Ambiental do Estado de São Paulo. Guia nacional de coleta e preservação de amostras: água, sedimento, comunidades aquáticas e efluentes líquidos. São Paulo: CETESB; Brasília: ANA. Disponível em:

$<$ http://arquivos.ana.gov.br/institucional/sge/CEDOC/Catalogo/2012/GuiaNacionalDeColeta. pdf>. Acesso em: 02 ago. 2018.

COSTA, M. O. Impactos ambientais a partir das atividades agrícolas em áreas instáveis da Serra da Jurema/PB. 2012. 30 f. TCC (Graduação em Geografia e Território:

Planejamento Rural, Urbano e Ambiental) - Universidade Estadual da Paraíba, Guarabira, 2012.

EMPLASA. Empresa Paulista de Planejamento Metropolitano S/A. Produtos Cartográficos. Ortofotos Digitais. 2010. São Paulo.

GALVANI, E.; LIMA, N. G. B. Fotografias hemisféricas em estudos microclimáticos: referencial teórico-conceitual e aplicações. Ciência e Natura, v. 36, p. 215-221, 2014. Disponível em: <http://oaji.net/articles/2017/1602-1487593551.pdf >. Acesso em 14 set. 2018.

GARCIA, J. C. et al. Fontes de adubação potássica na lixiviação de potássio em neossolo quartzarênico. Revista Eletrônica Thesis, v. 24, p. 76-89, 2015. Disponível em: <http://www.cantareira.br/thesis2/ed_24/materia5.pdf>. Acesso em 30 ago. 2019.

GARCIA, J. M. et al. Uso de fotografias hemisféricas para avaliação da qualidade ambiental na Mata de Santa Genebra, Campinas-SP, Brasil. Ciência Florestal, v. 28, n. 1, p. 175-190, 2018. http://dx.doi.org/10.5902/1980509831651

GROSTEIN, M. D. Metrópole e expansão urbana: a persistência de processos insustentáveis. São Paulo em Perspectiva, v. 15, n.1, p. 13-19, 2001. http://dx.doi.org/10.1590/S0102-88392001000100003

HORBE, A. M. C. et al. Contribuição à hidroquímica de drenagens no município de Manaus AM. Acta Amazônica, v. 35, p. 119-12, 2005. http://dx.doi.org/10.1590/S0044$\underline{59672005000200002}$

HULSMEYER, A. F.; MACEDO, S. S. APPs urbanas e as mudanças no Código Florestal: diretrizes para a legislação municipal. In: X Colóquio Quapá-SEL, Brasília, 2015.

KIEHL, E. J. Manual de edafologia: relações solo planta. 1979. São Paulo: Ceres. 
GARCIA, J. M.; LONGO, R. M.

Análise de impactos ambientais em Área de Preservação Permanente (APP) como instrumento de gestão em rios urbanos

KLEIN, C.; AGNE, S. A. A. Fósforo: de nutriente à poluente!. Revista Eletrônica em Gestão, Educação e Tecnologia Ambiental, Santa Maria, v. 8, n. 8, p.1713-1721, 2013. Disponível em: <https://periodicos.ufsm.br/reget/article/viewFile/6430/pdf >. Acesso: 31 jul. 2019.

LADWIG, N. I.; DAGOSTIM, V.; BACK, A. J. Análise da paisagem da região carbonífera do estado de Santa Catarina, Brasil, realizada com imagens de satélite. Ra'eGa, v. 43, p. 93107, 2018. http://dx.doi.org/10.5380/raega.v43i0.50813

LIMA, W. P.; ZÁKIA, M. J. B. As Florestas Plantadas e Água: Implementando o conceito de Microbacia Hidrográfica como Unidade de Planejamento. São Carlos: Rima Editora, 2006.

LOBÓN, G. S. et al. Influência das chuvas na qualidade da água distribuída ao consumo humano. Anais da Exposição de Experiências Municipais em Saneamento, Poços de Caldas, MG, Brasil, 19, 2015. Disponível em:

<http://www.trabalhosassemae.com.br/sistema/repositorio/2015/1/trabalhos/5/1/t1t1e1a2015. pdf >. Acesso em 24 nov. 2018.

LONGO, R. M. et al. Environmental indicators in forest fragments from urban watershed. WIT Transactions on Ecology and the Environment, v. 215, p. 121-132, 2018. http://dx.doi.org/10.2495/EID180111

LONGO, R. M. et al. Environmental quality in urban forests in Campinas - Sao Paulo State/Brazil. International Journal of Environmental Impacts, v. 2, n. 2, p. 117-130, 2019. http://dx.doi.org/10.2495/EI-V2-N2-117-130

LUZ, L. M. et al. Estudo geoambiental em bacias urbanas em Belém - PA. Boletim Amazônico de Geografia, v. 1, n. 2, p. 145-160, 2014. http://dx.doi.org/10.17552/23587040/bag.v1n2p145-160

MENEZES, J. P. C. et al. Relação entre padrões de uso e ocupação do solo e qualidade da água em uma bacia hidrográfica urbana. Engenharia Sanitária e Ambiental, v. 21, n. 3, p. 519-534, 2016. http://dx.doi.org/10.1590/S1413-41522016145405

METZGER, J. Estrutura da paisagem: o uso adequado de métricas. In: CULLEN JUNIOR, L.; PÁDUA, C. V.; RUDRAN, R. Métodos de estudos em biologia da conservação e manejo da vida silvestre. Curitiba, Editora da Universidade Federal do Paraná, 2003.

OLIVEIRA, J. S. S. Índices de vegetação (NDVI, IVAS, IAF, NDWI) como subsídio à gestão do uso e ocupação do solo na zona de amortecimento da Reserva Biológica de Saltinho, Pernambuco. Dissertação de mestrado, Universidade Federal de Pernambuco, Recife, PE, Brasil. 2013. Disponível em: <https://repositorio.ufpe.br/handle/123456789/10607>. Acesso em: 31 jul. 2019.

OLIVEIRA, T. H. et al. Avaliação espaço-temporal do Índice de área foliar e impacto das atividades antrópicas na Reserva Ecológica Estadual Mata São João da Várzea, Recife - PE. Anais do Simpósio Brasileiro de Sensoriamento Remoto, Curitiba, PR, Brasil, 15, 2011. 
GARCIA, J. M.; LONGO, R. M.

Análise de impactos ambientais em Área de Preservação Permanente (APP) como instrumento de gestão em rios urbanos

Disponível em:

<http://marte.sid.inpe.br/col/dpi.inpe.br/marte/2011/07.06.17.53/doc/p0525.pdf $>$. Acesso em 21 ago. 2019.

PEDROSO NETO, J. C. Análise do solo: determinações, cálculos e interpretação. Minas Gerais: EPAMIG, 2012. Disponível em: <http://docplayer.com.br/25596151-Analise-do-solodeterminacoes-calculos-e-interpretacao.html>. Acesso em 16 nov. 2018.

PIASENTIN, A. M. Índice de Qualidade da Água - IQA da bacia contribuinte do reservatório Tanque Grande, município de Guarulhos, SP. 2009. 165 f. Dissertação (Mestrado em Análise Geoambiental) - Universidade Guarulhos, Guarulhos, 2009.

RAIJ, B. V. et al. Recomendações de adubação e calagem para o Estado de São Paulo. Campinas: Instituto Agronômico \& Fundação IAC, 1997. (Boletim Técnico 100).

RONQUIM, C. C. Conceitos de fertilidade do solo e manejo adequado para as regiões tropicais. Campinas: Embrapa Monitoramento Por Satélite, 2010.

SANTOS, J. S. M. Análise da paisagem de um corredor ecológico na Serra da

Mantiqueira. Dissertação de mestrado, Instituto Nacional de Pesquisas Espaciais, São José dos Campos, SP, Brasil. 2002.

SÃO PAULO. Decreto Estadual 10.755 de 22 de novembro de 1977. Dispõe sobre o enquadramento dos corpos d'água receptores na classificação prevista no Decreto n. 8.468 (1), de 8 de setembro de 1976, e dá providências correlatas. Diário Oficial do Estado, São Paulo, 22 de novembro de 1977. Caderno Executivo 1. p. 7. Recuperado em 28 novembro, 2018, de https://www.al.sp.gov.br/repositorio/legislacao/decreto/1977/decreto-1075522.11.1977.html

SILVA, A. E. P. et al. Influência da precipitação na qualidade da água do Rio Purus. Acta Amazônica, v. 38, n. 4, p. 733-742, 2008. http://dx.doi.org/10.1590/S0044$\underline{59672008000400017}$

SILVA, A. P. M.; BARBOSA, A. A. Validação da função mancha de inundação do SPRING. Anais do Simpósio Brasileiro de Sensoriamento Remoto, Florianópolis, SC, Brasil, 13, 2007. Disponível em:

<http://marte.sid.inpe.br/col/dpi.inpe.br/sbsr@80/2006/11.15.21.46.50/doc/5499-5505.pdf>. Acesso em: 16 ago. 2019.

SILVA, D. D. E.; FELIZMINO, F. T. A.; OLIVEIRA, M. G. Avaliação da degradação ambiental a partir da prática da cultura do feijão no município de Tavares-PB. Holos, v. 8, p. 148-165, 2015. Disponível em: <http://www2.ifrn.edu.br/ojs/index.php/HOLOS/article/view/2063/1318>. Acesso em: 08 jul. 2019.

SOUSA, D. M. G.; LOBATO, E. (Ed.). Cerrado: correção do solo e adubação. Brasília: Embrapa Informação Tecnológica, 2004. 
GARCIA, J. M.; LONGO, R. M.

Análise de impactos ambientais em Área de Preservação Permanente (APP) como instrumento de gestão em rios urbanos

SOUSA, E. M. S.; FERREIRA, E. A.; MORAES, M. V. A. R. Análise da intervenção antrópica no balneário Curva São Paulo em Teresina - PI. REGNE, v. 2, Edição Especial, p. 1058-1066, 2016. Disponível em:

$<$ https://periodicos.ufrn.br/revistadoregne/article/view/10568/7485>. Acesso em: 19 nov. 2018 .

SOUSA, J. S. Áreas de Preservação Permanente Urbanas: mapeamento, diagnósticos, índices de qualidade ambiental e influência no escoamento superficial. Estudo de caso: Bacia do Córrego das Lajes, Uberaba, MG. Dissertação (Mestrado em Engenharia Civil), Universidade Federal de Uberlândia, Uberlândia, MG, Brasil. 2008. Disponível em: <https://repositorio.ufu.br/bitstream/123456789/14120/1/Joyce.pdf >. Acesso em: 18 nov. 2018.

SOUZA, A. D. G.; SOUZA, A. H. A influência da área urbana sobre a qualidade da água na bacia hidrográfica do Ribeirão dos Poços (Poços de Caldas, MG). HOLOS Environment, v. 15, n. 2, p. 139-151, 2015. http://dx.doi.org/10.14295/holos.v15i2.9441

SOUZA, C. A. et al. Correlação entre variáveis abióticas e biótica em água de abastecimento público em Goiás. Anais do Congresso Interamericano de Engenharia Sanitária e Ambiental, São Paulo, SP, Brasil, 27, 2017. Disponível em:

<https://www.tratamentodeagua.com.br/wp-content/uploads/2018/06/I-376.pdf >. Acesso em: 02 ago. 2019.

TEIXEIRA, P. C. et al. (Ed.). Manual de métodos de análise de solo. Brasília: Embrapa Solos, 2017.

TOGNON, A. A., DEMATTÊ, J. L. I.; DEMATTÊ, J. A. M. Teor e distribuição da matéria orgânica em latossolos das regiões da floresta amazônica e dos cerrados do Brasil central.

Scientia Agricola, v. 55, n. 3, p. 343-354, 1998.

TORRES, R. B.; ADAMI, S. F.; COELHO, R. M. (Org.). Atlas socioambiental da bacia do ribeirão das Anhumas. Campinas: Pontes Editores, 2014. Disponível em:

<http://www.iac.sp.gov.br/atlasanhumas/>. Acesso em: 24 abr. 2019.

YOSHIOKA, M. H.; LIMA, M. R. Experimentoteca de solos: pH do solo. Paraná: UFPR, 2005. Disponível em:

<http://mecdb3.c3sl.ufpr.br:8080/xmlui/bitstream/handle/123456789/2179/ph do

solo.pdf?sequence $=1$ > . Acesso em: 29 maio 2018 .

Autoras

Joice Machado Garcia - Possuiu Graduação em Engenheira Ambiental e Sanitarista pela Pontifícia Universidade Católica de Campinas (PUC-Campinas). Atualmente é Mestranda e Bolsista CAPES do Programa de Pós-Graduação em Sistemas de Infraestrutura Urbana pela Pontifícia Universidade Católica de Campinas (PUC-Campinas). 


\section{GARCIA, J. M.; LONGO, R. M.}

Análise de impactos ambientais em Área de Preservação Permanente (APP) como instrumento de gestão em rios urbanos

Regina Márcia Longo - Possui Graduação em Agronomia pela Universidade Estadual Paulista Júlio de Mesquita Filho (UNESP), Mestrado e Doutorado em Engenharia Agrícola pela Universidade Estadual de Campinas (UNICAMP). Docente e Pesquisadora do Programa de Pós Graduação em Sistemas de Infraestrutura Urbana pela PUC-Campinas (Centro de Ciências Exatas, Ambientais e de Tecnologia - CEATEC).

Artigo recebido em: 05 de fevereiro de 2020.

Artigo aceito em: 14 de abril de 2020.

Artigo publicado em: 20 de abril de 2020. 